\title{
Advanced analysis of a space structure retrofit for an ash-tank
}

\author{
A. Ivan, M. Ivan \& I. Both \\ University Politehnica of Timisoara, Romania
}

\begin{abstract}
In this paper we analyze a structure's response to new loadings in conformity with the new codes. In order to be able to come to a relevant conclusion we analysed three cases: a) strengthening the elements so that it keeps the same configuration, b) strengthening the elements and modifying the moment resisting frames into braced frames and c) reconstruct the entire structure with new elements. By applying the new codes we have analysed the results and we present the conclusions and the best and optimum solution for this particular case.
\end{abstract}

Keywords: retrofit, comparison to old codes, structure response, moment resisting frames, braced frames, sustainability.

\section{Introduction}

The Rovinari energetic complex in Romania is one of the biggest producers of electric (1320 MW) and thermal energy using coal as primary source of fuel. That is why in order to comply with the requirements of the Plan for the implementation of the EU Directive 1999/31 on storage of residual waste, it is imperative to introduce certain installations for the evacuation of coarse slag and ash, by using the technology of the self-hardening fluid. There are four energetic blocks each of $330 \mathrm{MW}$. For each block the ash and the slag are collected in a silo of $500 \mathrm{~m}^{3}$. This silo leans against a metallic structure, which is to be analysed in this paper. On this structure, supplementary installations for the evacuation of coarse slag and ash have to be mounted. Because of the short time at our disposal and because the silos cannot be dismounted, it is imperative to find a solution to retrofit the existent metal structure without interrupting the production process. The existent metal structure was designed in 1972 and that is 
why a thorough investigation has to be made in order to find out its response to new additional loading: permanent, technological, utile, seismic, wind and snow and to the combinations of these factors.

It is very important to make a full analysis for power plants, since the loadings are changing once the technology changes. Besides this, the codes for the seismic actions were changed and the structural behaviour is different if we consider the magnitude (i.e. the intensity of the base force) and also the displacement (concerning the development of the plastic hinges).

\section{Structural configuration}

The structure studied in this case (Figure 1) was designed in 1972. At that time the codes for earthquake design were not very accurately studied as they are nowadays. Still the structure was also designed for seismic actions, thus resulting a reserve for the design at permanent and variable loads. The increase of the combination factors for permanent and variable loads, according to new codes, does not lead to a strengthening of existing structure. But the response of the structure to lateral seismic forces is significantly different compared to the one assumed in the initial design of the structure.

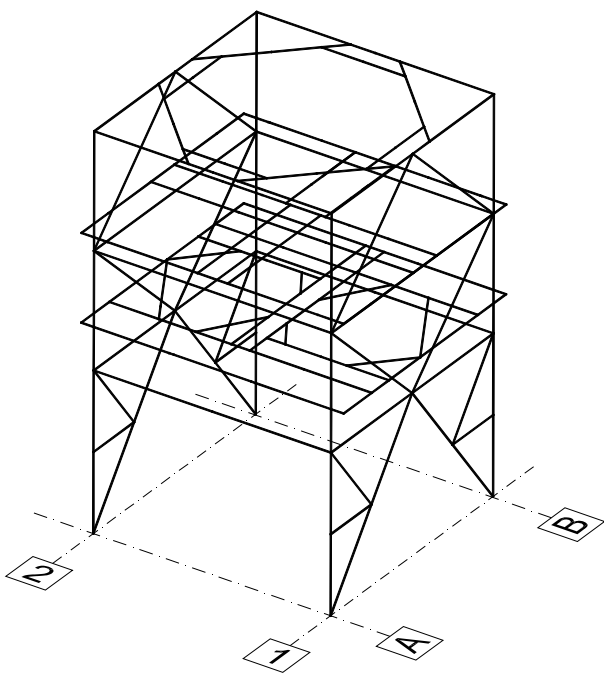

Figure 1: $\quad$ Spatial structure.

The structure has four frames: two are moment resisting frames and two are braced frames. Horizontally, the structure has 3 platforms at $+7.6 \mathrm{~m},+11.3 \mathrm{~m}$, + $15.5 \mathrm{~m}$ and also the elements from a previous platform at the height of $+6.3 \mathrm{~m}$. Considering the entire structure $80 \%$ of the elements are superficially corroded, consequently rust has to be removed. It is obvious that the cleaning of the rust involves a lot of labour. The evaluation of this work will be made after the presentation of the solutions made. 
The objectives of this paper are: to evaluate the seismic performance of the existing individual building structure, to describe the approach in selecting the necessary corrective measures in order to meet the requirements of the new standards and codes [1].

\section{Conceptual design}

\subsection{The first analysis}

The first analysis was performed in order to evaluate the response of the existing structure with no structural modification, but with new loadings and considering the previous code for the seismic action. The analysis was a linear elastic one with lateral forces.

The result for this analysis was: none of the elements exceeded the admissible resistance and furthermore the strength reserve for the columns is considerably greater than for the dissipative elements of the structure.

For the seismic actions, the ratio, between the effective stress and the admissible stress for beams in the frames, is 0.5 maximum, while for the columns is of 0.26 . Basically, the elements of the structure are more stressed because of the combination of loads that does not include the seismic action considered to be the one from previous codes.

\subsection{The second analysis}

The second analysis considers the structure response to the actual seismic actions according to the new codes. The ground acceleration $\mathrm{a}_{\mathrm{g}}$ was taken as $0.12 \mathrm{~g}$, the elastic response spectrum for horizontal components of ground acceleration is presented in Figure 2.

Taking into consideration [1] and the checking performed [2, 3], it resulted that all the columns need to be strengthened as they were checked for a combination that included the over strength for non-dissipative elements. Because of the new seismic provisions other elements have to be strengthened as

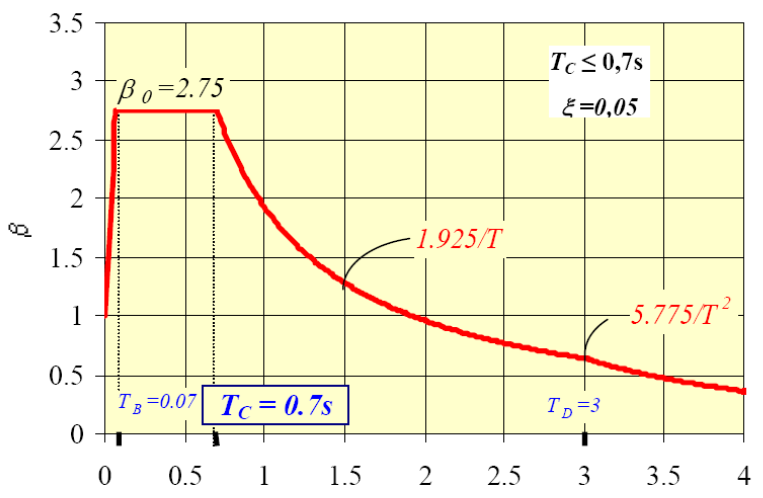

Figure 2: Elastic response spectrum. 

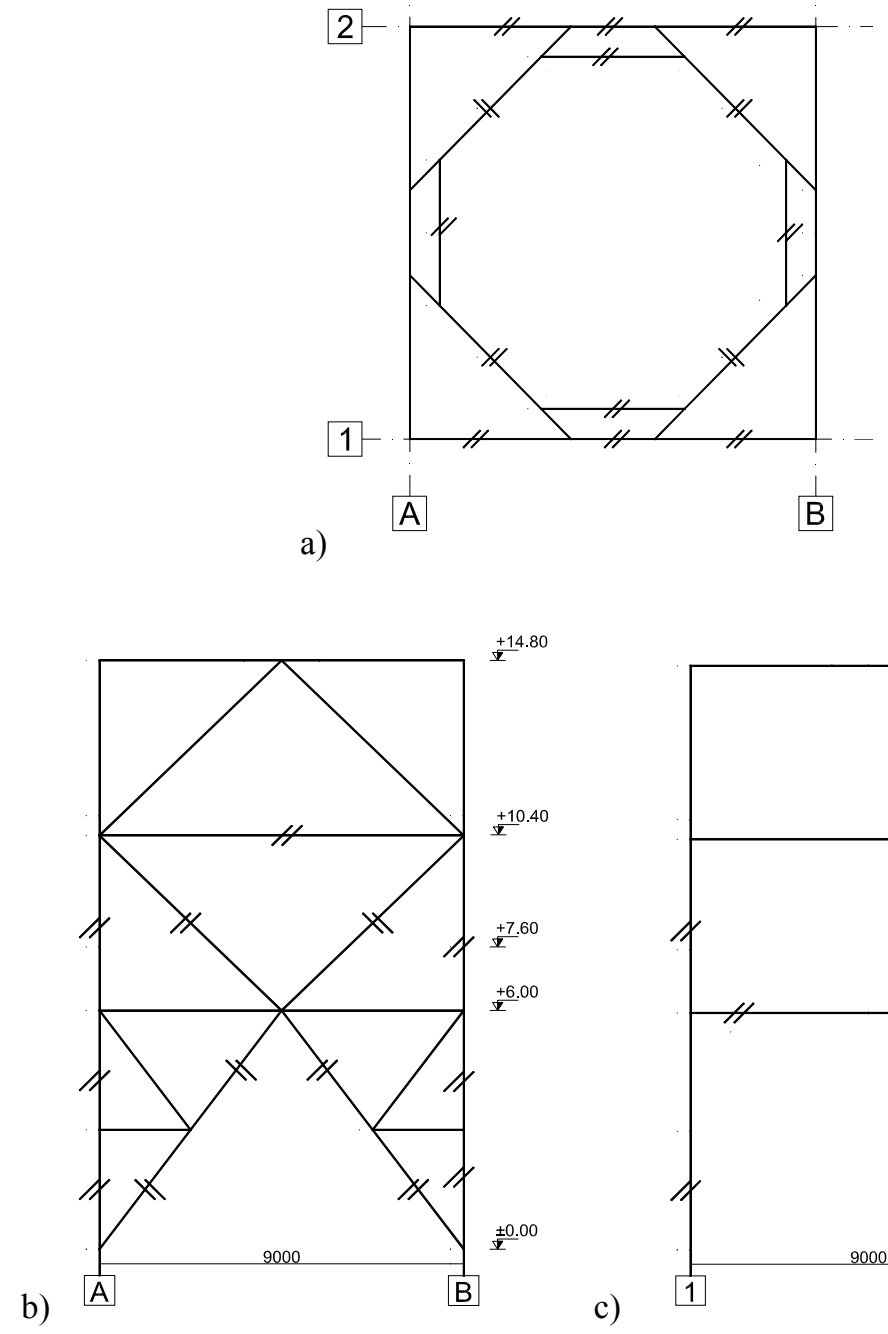

c)

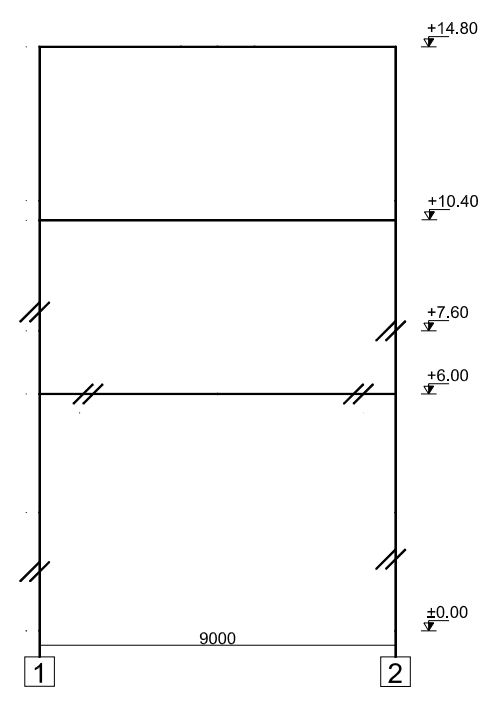

Figure 3: $\quad$ a) Floor $+15.5 \mathrm{~m}, \mathrm{~b}$ ) braced frame, c) MRF.

well: the bracings at the lower and intermediate part of the building (figure $3 \mathrm{~b}$ ), the beams that support the ash tank at the top of the building (figure 3a) and the beam in the MRF (figure 3c).

\subsection{The third analysis}

The third analysis includes the modification of the structural system by the addition of some new structural elements namely: bracings in the Moment Resisting Frame (Figure 4). This helps to reduce the moments in the columns for the major axis but it also changes the fundamental period of structure. If for the case of initial 


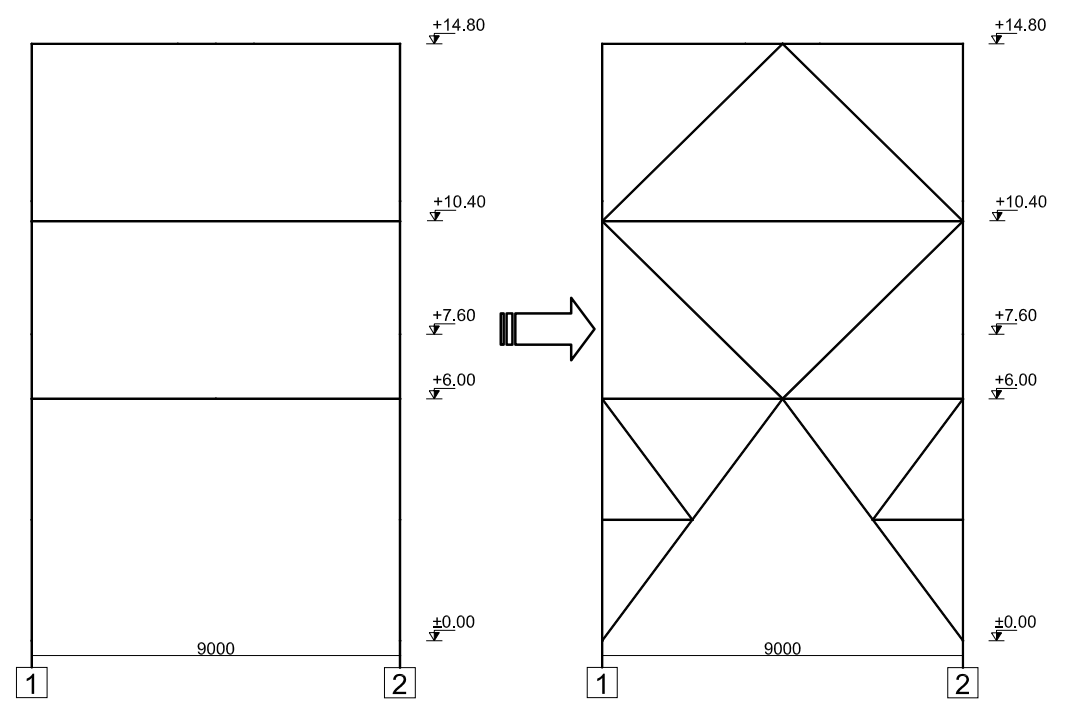

Figure 4: Structural modification.

structure, the period was around 1.6 seconds and the movement was in the plane of the moment resisting frame, for the complete braced structure, the first mode of vibration has a period of $0.68 \mathrm{~s}$ which is near the eigen period of the ground.

It also has to be reminded that this operation is technologically allowed. If the railway that goes under the structure would still have to remain functional or the tanks that have been recently installed were too large, this option would not have been taken into account.

The results from this analysis indicated a smaller value for the ratio between the effective stress and the capacity for all the elements. With these considerations the structure still needs to be strengthened, but the steel quantity needed for strengthening is smaller. These elements are presented in Figure 5.

In this solution the beams of the moment resisting frames become over dimensioned and the bracings are designed from the slenderness conditions. That why this is not the optimum solution.

\subsection{The fourth analysis}

The last choice of analysis was to consider the demolition of the old structure and the erection a new one $[4,5]$. For this new structure the elements with flaws in the initial design (over-strengthened bracings, weak joints) are removed and the elements and joints are redesigned according to the new codes. The results are presented in the following sections.

\section{Strengthening solutions}

The elements that need to be strengthened are presented in this section. 
The bracings at the lower and the intermediate part need more material, but also their slenderness has to be improved because of their length. Another pair of angle profile was used as shown in Figure 6.

The strut at $+10.4 \mathrm{~m}$ is a $\mathrm{U} 300$ and although it was subjected to tension only, it has stresses greater than the admissible limit and a too high slenderness.
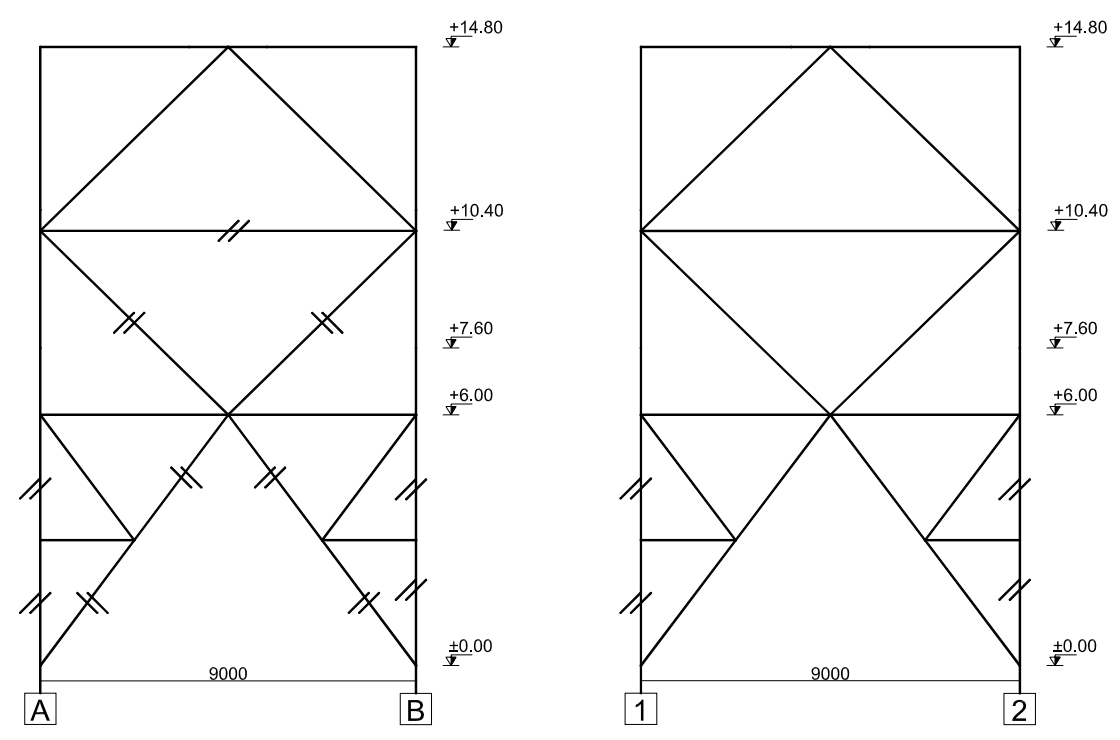

Figure 5: Overstressed elements for braced structure.

\begin{tabular}{|l|c|c|}
\hline & Initial section & Strengthened section \\
\hline \hline \multirow{3}{*}{ Bracings } & & \\
& $2 \times 120 \times 11 / 15$ & \\
& $2 \times 120 \times 11 / 15$ \\
\hline
\end{tabular}

Figure 6: Bracing strengthening.

Because of that, the bracings at the top level (HEB 300) transmitted great forces in the columns. By strengthening this strut (Figure 7) the deformations in the columns and the stresses at $+10.4 \mathrm{~m}$ were reduced significantly.

The beams at the top level which support the tank are greatly influenced by the seismic actions. The permanent and live loading the ratio between the stress and resistance is around 0.35 while in combination with the seismic action this value goes over 1.0 thus requiring improvements (Figure 8). 


\begin{tabular}{|c|c|c|}
\hline & Initial section & Strengthened section \\
\hline Strut & U300 & \begin{tabular}{|l|}
$\mid$ \\
U300+HEB400
\end{tabular} \\
\hline
\end{tabular}

Figure 7: Strut strengthening.

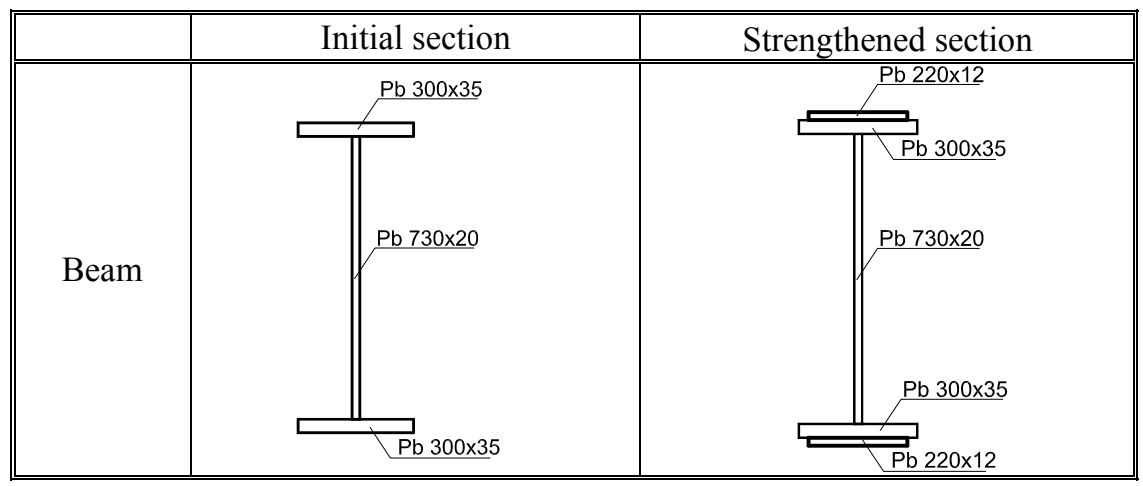

Figure 8: Beam strengthening.

The columns were made of welded plates and the rust is very deep within the material in the supports. The stresses would not be over limits if the initial section was intact, as it stands now for the sections at the base of the columns resulting the strengthening is a necessity (Figure 9).

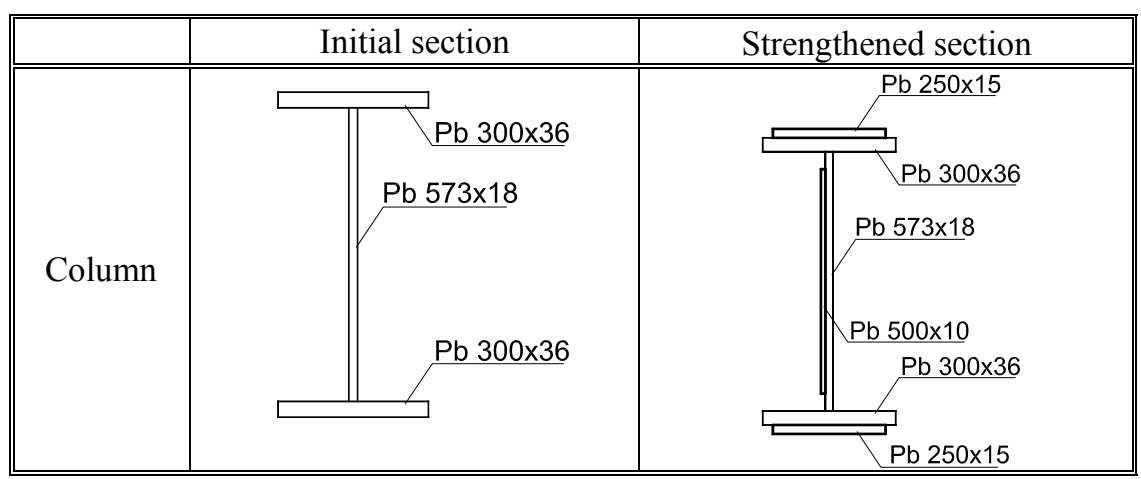

Figure 9: Column strengthening. 


\section{Sustainability considerations}

Sustainability means an increase in the economical development (maintain and improve profitability), social policy (improving safety and health, improving quality of the built environment) and environment protection (energy usage, operational usage, embodied energy, emissions from manufacturing, processes, waste to surroundings, and pollution) [6].

\subsection{Economic prosperity (profit)}

The economic prosperity refers to maintaining or improving profitability. This section will not take into account the profitability of using certain technology for desulphurization.

For what the existing structure is concerned it can no longer be considered sustainable. Rust has affected the ash tubes and any intervention upon the structure, would require an evaluation which would lead to the modifications above shown.

The Steel Recycling Institute gathered information that electric arc furnaces can obtain the same steel by using $80 \%$ of scrap [6]. It results that for a new structure, 53 tones can be obtained by recycling the old structure.

The material consumptions for each case are presented in Table 1.

Table 1: Material consumptions.

\begin{tabular}{|l|c|c|c|c|}
\hline Case & $\begin{array}{c}\text { Total weight } \\
\text { of structure }\end{array}$ & $\begin{array}{c}\text { Strengthening } \\
\text { parts }\end{array}$ & $\begin{array}{c}\text { Initial } \\
\text { structure }\end{array}$ & $\begin{array}{c}\text { Usage of initial } \\
\text { structure }\end{array}$ \\
\hline S & 99.67 tones & 33.46 tones & 66.21 tones & $66.4 \%$ \\
\hline SM & 81.13 tones & 14.92 tones & 66.21 tones & $81.6 \%$ \\
\hline NS & 67.68 tones & - & - & $78.3 \%$ (recycled) \\
\hline
\end{tabular}

S - Strengthening; SM - Structural modification; NS - New Structure.

\subsection{Social capital (people)}

It was evaluated the necessary labour for one tone of steel in each analysed case. As it can easily be seen in Table 2 a greater quantity of labour is required for the new components that strengthen the structure than for the refurbishment of the existing elements and for their preparation in order to be strengthened.

In Table 2, "new" represents the labour done for elements that strengthen the structure and "initial" represents the labour done for the existing elements.

In what the safety of the workers is concerned there cannot be any differences between the situations taken into account. The health of the workers is negatively influenced in the case in which the existing structure has to be refurbished and prepared to be strengthened because of the rust and the dust that have to be eliminated. 
Table 2: $\quad$ Amount of labour.

\begin{tabular}{|c|c|c|c|c|c|c|c|}
\hline Case & $\begin{array}{c}\text { Man'hour } \\
\text { (new) }\end{array}$ & $\begin{array}{c}\text { Man·hour } \\
\text { (initial) }\end{array}$ & $\begin{array}{l}\text { New } \\
\text { parts }\end{array}$ & $\begin{array}{c}\text { Initial } \\
\text { structure }\end{array}$ & $\begin{array}{c}\text { Man'hour } \\
(1 \times 3)\end{array}$ & \begin{tabular}{|c|} 
Man'hour \\
$(2 \times 4)$
\end{tabular} & $\begin{array}{l}\text { Total } \\
(5+6)\end{array}$ \\
\hline 0 & 1 & 2 & 3 & 4 & 5 & 6 & 7 \\
\hline $\mathrm{S}$ & 11.41 & 2.28 & $\begin{array}{l}33.46 \\
\text { tones }\end{array}$ & $\begin{array}{l}66.21 \\
\text { tones }\end{array}$ & $\begin{array}{c}381.8 \\
\text { man·hour }\end{array}$ & \begin{tabular}{|c|}
150.9 \\
man·hour
\end{tabular} & $\begin{array}{c}532.7 \\
\text { man·hour }\end{array}$ \\
\hline $\mathrm{SM}$ & 11.41 & 2.28 & $\begin{array}{l}14.92 \\
\text { tones }\end{array}$ & $\begin{array}{l}66.21 \\
\text { tones }\end{array}$ & $\begin{array}{c}170.2 \\
\text { man·hour }\end{array}$ & \begin{tabular}{|c|}
150.9 \\
man·hour
\end{tabular} & $\begin{array}{c}321.1 \\
\text { man·hour }\end{array}$ \\
\hline NS & 11.41 & - & $\begin{array}{l}67.68 \\
\text { tones }\end{array}$ & - & \begin{tabular}{|c|}
772.2 \\
man·hour
\end{tabular} & - & \begin{tabular}{|c|}
772.2 \\
man·hour
\end{tabular} \\
\hline
\end{tabular}

Usually the quality of the building environment is superior for a new structure due to technological improvements applied to that structure. In our case the analysed structure is just the support for the supplementary installations required by the new non-pollution technology. The existing structure itself is not improved by the implemented technology.

\subsection{Environment protection}

Among the most important points to be considered for the environment protections are the following:

-Energy -building energy use;

-Embodied energy -materials;

-Operational energy -thermal efficiency;

-Pollution;

-Waste to landfill.

In our case, the first three items do not make a big difference, since they refer to a building for which the heat transfer towards the environment is almost nil. Inside the structure there will not be any heating devices.

The pollution data taken into account are from Table 1. According to the statistics for one tone of steel it is produced 0.9 tones of carbon emissions. It results that between the $\mathrm{S}$ and SM options the reduction of carbon emissions is 16.69 tones. If a new structure is manufactured it will give a production of 60.91 tones of carbon emissions. The other pollution factors (transportation, erecting with cranes) can be considered equal for all three cases, since the excess of material that needs to be transported might be compensated with the pollution for devices needed for the cleaning of the existing elements which are corroded.

Waste to landfill is predominant for the cleaning of the corroded elements since this rust cannot be recycled. The quantity of this waste is function to the corrosion on the entire structure.

\section{Results synthesis}

From the analysis performed in section 2, we can observe that there are only three cases that need to be taken into account since the first case does not meet 
the requirements for the actual code regarding strength and safety. The case where the structure remains the same will need more material for strengthening the elements, especially elements in the MRF, but also the bracings at the lower part of the structure. Bracings at the lower and intermediate part need more material but furthermore because of their length, their slenderness has to be reduced. The strut at height +10.4 has to be strengthened and thus a more rigid assemble of elements is obtained.

For the new configuration, the forces are transmitted at lower height of the columns distributing the moment with a smoother slope between the platforms.

The beams at the top level which support the tank are greatly influenced by the seismic actions, since for the permanent and variable loads, the ratio between the stress and resistance is around 0.35 while in combination with the seismic action this value goes over 1.0 requiring improvements.

The initial configuration needs more than twice the material used for the structural modification.

For strengthening and the refurbishment of the elements there is necessary more hours of labour than for the case of structural modification and less than for the case of erecting a new structure. Considering the health of the workers, the erection a new structure is the most advisable one.

Pollution is greater for a new structure than the other two cases.

\section{Conclusions}

Since this structure was designed mainly to the new seismic loading codes it has to be taken into consideration different technological process situations and restrictions also. Three structural configurations were analysed with three different results and responses.

The analysis has shown that the factors for efficiency, besides strength and serviceability, can alternate in the classification of these three cases. By summarizing the positive aspects of each case, the best solution is the change of the structural system. This can be achieved only if the railway under the structure is no longer necessary. If this is not possible the second solution could be the reconstruction of a new structure as the manufacture is almost the same, but the energy and the use of material is greater than for the strengthening of the structure without having to change the structural configuration.

Taking into consideration the data presented in the paper, one can choose the best solution for the seismic retrofit of such a structure only based on an accurate quantification of economic, social and environment aspects involved.

\section{References}

[1] Eurocode 8 Design of structures for earthquake resistance Part 3: Assessment and retrofitting of buildings

[2] Sarno, L.Di \& Elnashai A.S., Seismic retrofitting of steel and composite building structures, Report 02-01, September 2002 
[3] Bruneau, M., Uang, C.M. \& Whittaker, C.M. (1997). Ductile design of steel structures. McGraw Hill, New York, New York, USA.

[4] Ivan, M., Ivan, A., Stanciu, M. \& Popa, V., The influence of geometric imperfections generated by erection and production errors on the behaviour of steel tower, Proceedings of the $10^{\text {th }}$ International Conference on Metal Structures, Orizonturi Universitare, Timisoara, pp. 50-56, 2003

[5] Ivan, M \& Ivan, A., The rehabilitation of the runway of the $160 \mathrm{kN}$ overhead travelling crane from the machine room of Iron Gates I, Proceedings of the $10^{\text {th }}$ International Conference on Metal Structures, Orizonturi Universitare, Timisoara, pp. 44-50, 2003

[6] Barrett, R.B., Developing a Sustainable Business, NASCC 2009, Phoenix $1^{\text {st }}$ April 2009 